\title{
Innovating the food value chain
}

\author{
While global efforts to tackle hunger and other food-related crises are stepping up, Nature Sustainability and \\ the Cornell Atkinson Center for Sustainability convene a new Expert Panel focusing on system changes and \\ human agency.
}

F ood system is a concept, and a reality, which is rapidly gaining momentum within global sustainable development debates. The 2030 Agenda for Sustainable Development has indeed a strong focus on food as captured by SDG 2 'End hunger, achieve food security and improved nutrition and promote sustainable agriculture'. Research on food security and nutrition has informed how to increase the availability of food to satisfy the needs of a growing population, as well as how to improve food quality to achieve healthy nutritional outcomes. More is needed as hunger is still a pressing challenge as much as ensuring healthy diets globally. The environmental impacts of food have evolved into real crises and can no longer be left out of the global food agenda. Experts have produced mounting evidence about the chain effects of using pesticides, of deforesting land to farm, of food-driven greenhouse gas emissions and of plastic waste from food packaging to name only a few. But food is also a major source of livelihood to many at different levels, and research has amply documented the economic and social dimensions of food, including the increasing inequalities associated with access to healthy and sustainable food products.

And it's the intertwined nature of all these issues that has driven the focus on food systems. What exactly is a food system? Experts at the Food and Agriculture Organization (FAO) of the United Nations for example describe a food system as the whole range of actors involved in the various activities, including production, aggregation, processing, consumption and disposal, centred on food products coming from agriculture, forestry or fisheries, and rooted in the natural environment. They promote a holistic and integrated approach to better understand such a system. Of course, other definitions exist, but generally experts are embracing the complexity of food in order to develop more research along these lines. And producing better knowledge of the food system is no longer confined to academia as more players are participating - including practitioners, leaders from civil society organizations, indigenous groups, private and public companies and, increasingly joining in as knowledge co-producers, government representatives.

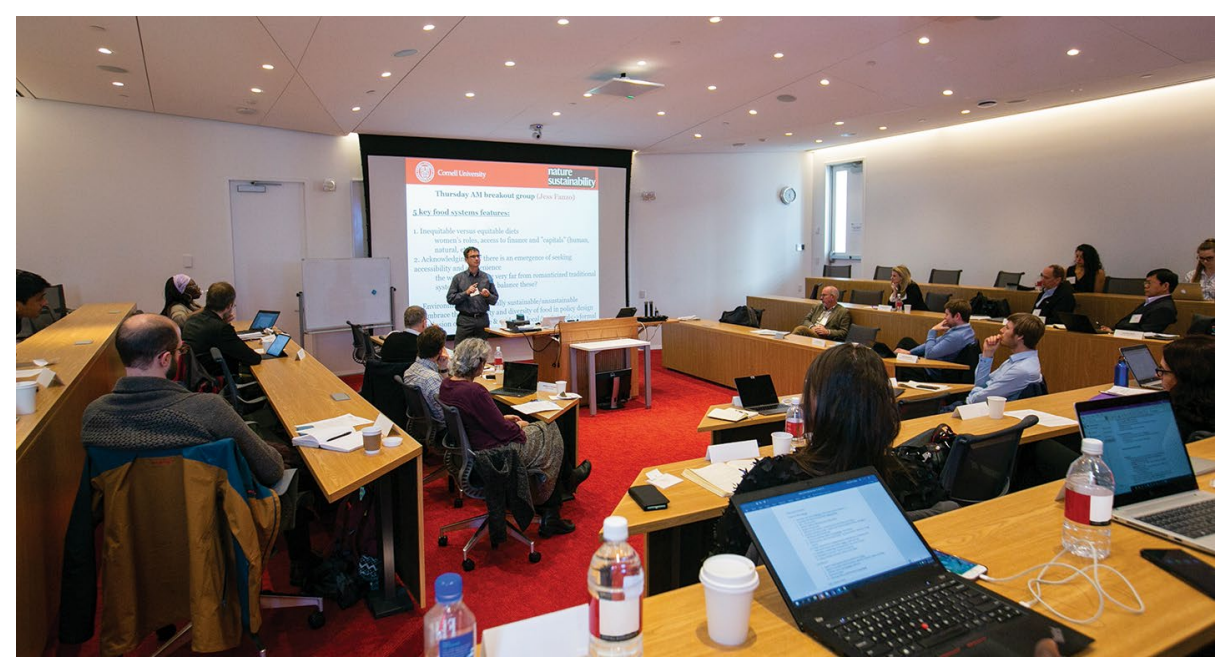

Credit: Image courtesy of Cornell University/Jesse Winter

Overall, the international debate is changing, with more and more emphasis on the systemic, integrated and complex nature of food, and the research landscape is adapting to the new challenges with more interdisciplinary research and academia increasingly reaching out to non-academics. The publishing world is responding, including at Springer Nature with the very recent and exciting launch of our sister journal Nature Food.

All this engagement is positive, necessary and reason for hope. But we, at Nature Sustainability, are hoping for more. SDG 2 mentions 'sustainable agriculture'. It's a critical step but partial. We are hoping for a bold change of narrative and emphasis around food. We are hoping for the international community to commit to deliver on the sustainability and the equity of food because it is not enough to learn about the complexity of the food system and to understand what is driving failure. We, as society, need to change the system radically in order to ensure that it fairly delivers food security and nutrition globally now and in the future.

The real milestone is therefore how to achieve a change of this magnitude. Nature Sustainability supports a vision of sustainable and equitable food through a focus on human agency. That means a focus on the numerous activities, and all the actors behind them, that add value to what people consume as food products. And such a focus is captured well by the 'food value chain' concept that includes actors engaged in upstream activities (developing and distributing farm inputs, farming and other primary production of unprocessed food), midstream activities (processing, distributing, retailing, regulating and providing food services) and downstream activities (consuming) around food. By embracing such a vision, efforts should be directed at identifying the critical innovations likely to trigger change across the food value chain and how to enable such innovations.

That is why this year we have convened a new Expert Panel jointly with the food security working group at the Cornell Atkinson Center for Sustainability titled 'Innovations to build sustainable, equitable, inclusive food value chains' and with the kind participation of Nature Food. The ambition shared by the 22 experts joining the panel from industry, academia and broadly civil society is to explore the feasible innovations likely to ameliorate the human and environmental outcomes of the food system. Panellists will work together throughout 2020 to identify and assess potential actions able to move the food value chain to a more inclusive, equitable and sustainable path. We will wait impatiently to learn about their recommendations.

Published online: 17 January 2020 https://doi.org/10.1038/s41893-020-0471-3 